\title{
Research on the Plateau Training Characteristics of Canoeing Athletes
}

\author{
Yabin He ${ }^{1, \text { a }}$, Shuai Liu ${ }^{2, b}$, Guoqin Jiang ${ }^{1, ~ c, ~ * ~}$ \\ ${ }^{1}$ School of Physical Education, Jianghan University, Wuhan 430056, China; \\ ${ }^{2}$ Wuhan Sport University, Wuhan 430056, China;

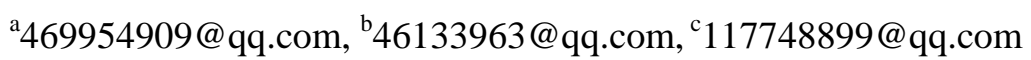 \\ *Author for correspondence: 117748899@qq.com
}

Keywords: Kayaking, physical training, biochemical index, monitoring

\begin{abstract}
Nowadays, with the rapid development of competitive sports, the technical level of each project is constantly improving. If it is necessary to get a breakthrough improvement in a sports event, simple training cannot be realized. For kayaking, the overall performance of athletes in our country is still far from the Australian countries. The competitive level of an athlete depends not only on the intensity of training but also on the physiological and biochemical indicators of science. Based on the data obtained, a reasonable, effective and feasible training method is formulated. The biochemical indexes of hemoglobin (Hb), blood urea (Bun) and creatine kinase (CK) during the winter training of a provincial athlete were studied in order to explore more reasonable training methods and methods and to analyze the physical training process of athletes The quality and effectiveness of scientific and effective control. At the same time, in order to improve the performance of canoe athletes, combined with the monitoring of sports biochemical indicators, using the methods of documentation, data statistics and interview to conduct research on the physical training of canoe athletes, Exercises in the training of the existing problems, and propose a scientific solution.
\end{abstract}

\section{Introduction}

Modern kayaking started in 1865 and was officially listed as an Olympic event at the 1936 Berlin Olympics. According to the domestic literature survey, the kayaking of our country was introduced in 1930, and then to the founding of new China, the state began to attach importance to the development of this sport. In 1954 at the Beijing Water Sports Games, set up a men's 1000 meters and 500 meters women's canoe game. In 1975, China began to participate in the World Championships. Since then, the rapid development of kayaking in the country, and vigorously the introduction of foreign advanced technology and training methods, so that the level of domestic kayak training has been improved stage, and in two Olympic Games in 04 and 08 achieved excellent Score. However, compared to some developed countries abroad, the kayaking in China is still relatively backward. At present, the research on kayaking is not paid much attention in China and can not meet the needs of the development of kayaking in our country. The training system is not systematic and lack of innovation. Second, in training monitoring, there is no reasonable use of relevant data for effective use. On the other hand, there is still a lack of personnel, size and popularity.

Since 2015, the state has promulgated a favorable policy on sports, which not only accelerated the development of sports in our country, but also aroused the attention of people from all walks of life to competitive sports. Among them, the water canoeing in our country was widely accepted by the outside world attention. With the passing of the Rio Olympic Games in 2016, our kayaking project has ushered in a new Olympic cycle. Our kayak team won medals at the Rio Olympic Games, but such achievements are not satisfactory. At the same time, we can see the huge gap between kayaking in China and European countries. The kayaking belongs to the type of speed-endurance sports which are the main types of physical fitness. The cycle of technical movement cycles is in the process of training. In the course of training, we must learn to use scientific monitoring and control, combine 
relevant biochemical indexes, train the athletes in a reasonable and effective manner, At the same time, it is necessary to innovate the training methods and find a breakthrough in effectively improving athletes' physical fitness.

Although the kayaking was introduced into our country earlier, its development speed was not satisfactory. There was still a huge gap between domestic athletes and European top athletes. Among them, there was the physical difference of body function, but the most obvious one was acquired physical training Inadequate. Kayaking is a fitness-led endurance-type sports, requiring athletes have a higher ability of aerobic metabolism and tolerance to lactic acid, while requiring athletes have a strong endurance strength, speed and strength of the continuity of power transmission, So athletes acquired physical training is crucial. Therefore, in this paper, through the study of the related biochemical indexes of winter training and pre-competition hemoglobin ( $\mathrm{Hb})$, blood urea and creatine kinase $(\mathrm{CK})$ in a province athlete, the training methods and biochemical indexes are effectively combined to discuss the correlation Indicators and training in general, and put forward effective physical training methods suitable for athletes, hoping to promote the rapid development of kayaking in China at the same time, strengthen young people kayaking physical training methods to improve athletic performance and help Coaches engaged in canoeing to develop a reasonable and effective training programs and implementation of the training plan to provide scientific data support and theoretical guidance, hoping to prepare our kayak athletes to provide scientific and technological support and help the Olympic Games, so that our skin Boat sports have their place in the national arena.

Modern dragon boat race has changed from the past folk performances into a sports competition. In the past ten years, with the development of the sport's growth, game time is no longer confined to the day of the Dragon Boat Festival, the prize is more and more high, the level of organization is more and more high, which makes the strength of the team have more chances. Plus, all kinds of media are also actively involved in the game, for the game, so that more and more sponsors to see the business opportunities contained in them, so that the professionalization of the Dragon Boat Sports has become possible.

Sponsored by the national sports administrative guidance center, Chinese Dragon Boat Association and CCTV sports channel cooperation and the Chinese Dragon Boat Race Dragon boat tournament since 2011. After the promotion and development of 4 years, the Dragon Boat Sport Watch and competition get a full range of ascension and the Dragon Boat Sport and Dragon Boat Club is booming. The inheritance and development of the Dragon Boat Movement will play an important role in the transmission of the traditional culture of the Chinese nation and the promotion of the national fitness program.

\section{Method}

\subsection{Observation Method}

Observational method refers to a method by which a researcher can obtain information by studying the outline or observation table according to a certain research purpose and directly observing the studied subject with his own senses and auxiliary tools. Scientific observation is purposeful and planned, systematic and repetitive. In this paper, by observing the kayaker in a province with the way of team training, we can understand the status quo, training status and biochemical indexes of athletes and provide effective data support for the writing of the thesis.

\subsection{Investigation Method}

Investigation is the most used research method in scientific research. It is a purposeful, systematic and systematic method of collecting material about the realities or historical conditions of an object of study. This article interviewed experts, coaches, researchers and athletes of canoe team in a province through interview, questionnaire survey, telephone interviews and follow-up training to understand athlete's performance, training mode, biochemical index changes and so on. 


\subsection{Documentation Method}

The literature method is based on a certain research purpose or topic, by consulting the literature to obtain information, so as to correctly and fully understand a research method to master the research question. I consulted the Chinese periodical full-text database, Wanfang database, China Journal Net and other websites, access to search and retrieval of kayaking training and scientific monitoring and other related literature, as the basis for the study of the paper reference.

\subsection{Statistical Analysis}

Statistical analysis refers to the research object by the scale, speed, scope, extent and other quantitative relationship analysis, understanding and revealing the interrelationships between things, changes and trends in order to achieve the correct interpretation of things and predict a Research method. In this paper, Excel and SPSS11.5 software are used to carry out statistics on the training of sports and biology during winter training and pre-competition training of a provincial canoeing team to provide data support for the dissertation writing and to ensure the scientific Sex and rigor.

\section{Results}

In general, hemoglobin is a protein that can transport oxygen and carbon dioxide, and participate in the body's acid-base balance, which is an important component of red blood cells, is an important protein in red blood cells, the concentration of red blood cells up to $34 \%$, Accounting for $90 \%$ of the total protein in red blood cells. The amount of hemoglobin on the athletic ability of athletes have a great influence, all in the training, the measurement and monitoring of hemoglobin is essential. According to the related research, the hemoglobin level of female canoe athletes is about 110-150g / L. Men's canoeists hemoglobin value of $120-160 \mathrm{~g} / \mathrm{L}$ or so. This time for six outstanding male athletes twice 1000 meters long distance test, and the measured hemoglobin and exercise scores were compared.

Table 1 Hemoglobin measurements

\begin{tabular}{ccccc}
\hline athlete & HB1 & results1 & HB2 & results2 \\
\hline WXM & $172.8 \pm 1.0$ & $3^{\prime} 56^{\prime \prime}$ & $175.5 \pm 1.0$ & $3^{\prime} 41^{\prime \prime}$ \\
QS & $169.0 \pm 1.0$ & $3^{\prime} 59^{\prime \prime}$ & $170.1 \pm 1.0$ & $3^{\prime} 53^{\prime \prime}$ \\
LZT & $160.8 \pm 1.0$ & $4^{\prime} 02^{\prime \prime}$ & $166.0 \pm 1.0$ & $3^{\prime} 50^{\prime \prime}$ \\
LSL & $158.5 \pm 1.0$ & $4^{\prime} 10^{\prime \prime}$ & $165.8 \pm 1.0$ & $3^{\prime} 56^{\prime \prime}$ \\
ZHR & $156.8 \pm 1.0$ & $4^{\prime} 13^{\prime \prime}$ & $159.6 \pm 1.0$ & $4^{\prime} 01^{\prime \prime}$ \\
WZ & $157.0 \pm 1.0$ & $4^{\prime} 01^{\prime \prime}$ & $160.0 \pm 1.0$ & $3^{\prime} 59^{\prime \prime}$ \\
\hline
\end{tabular}

As the test method of hemoglobin is relatively simple, reliable and stable, it is widely used in different sports and is one of the most widely used biochemical indexes in sports training. According to this study, when hemoglobin is kept in the human body at a relatively high level, the competitive ability of athletes will be significantly improved because the more hemoglobin is in the human body, the more oxygen is contained in the human body, and then the stronger the aerobic capacity, so if hemoglobin can be maintained in the athlete's body in a certain range, can effectively improve the athletic ability of athletes and improve athletic performance.

Nowadays, biochemical indicators are widely used in the training of various sports. To formulate a reasonable, effective and realistic training plan must be formulated in accordance with the biochemical indicators measured in training. Kayaking is a type of fitness-led endurance-speed sports that require athletes to have high aerobic capacity and ability to tolerate lactic acid, so for kayaking, biochemical measurements are even more indispensable. Through the measurement of each index of athletes, we can keep abreast of the athlete's physical function status and provide a direct reference for the athletic training team. First, the training load can be adjusted. Through the biochemical indicators, the athlete's adaptability to the exercise load can be understood as an adjustment The basis of exercise load, more conducive to the athlete's competitive ability. Second, through biochemical 
indicators to understand the recovery of athletes after training and injuries, effectively prevent the occurrence of athlete injuries and actively improve the athlete's body condition

\section{Discussion and Conclusion}

The monitoring of biochemical indicators is an indispensable part of sports teams in training. If there is no scientific indicator to weigh training plans, then this training is unscientific, unreasonable and not rigorous. This study more clearly proves that hemoglobin can effectively improve the athletic performance and athletic performance of athletes when the content of the hemoglobin in the human body is maintained within a relatively high range, and then improve the athletic performance of athletes. The content of blood urea nitrogen is mainly Training related. By knowing the change of athlete's blood urea content, we can know how athletes adapt to the amount of exercise. The value of blood lactate is an important index to evaluate aerobic and anaerobic metabolism of athletes. Blood lactate can effectively assess the athlete's lactate tolerance, lactate tolerance of the higher mobilization, the greater the anaerobic capacity.

In the findings of this study, the measurement of biochemical indicators of athletes is essential for the development of a reasonable training program, so we should attach importance to the determination of biochemical indicators of athletes in daily training, and finishing more after the measurement, Rely on changes in data to develop effective training programs, and according to changes in indicators reasonable judgments of athletes on the intensity of exercise load tolerance in order to observe the physiological changes of athletes to avoid over-training. At the same time to establish a more comprehensive database of athletes for the coaches to develop, implement and adjust the training program to provide scientific and effective data support and theoretical guidance.

\section{References}

[1] M Sheykhlouvand, SC Forbes, Aerobic capacities, anaerobic power, and anthropometric characteristics of elite female canoe polo players based on playing position. Sport Sciences for Health, Vol. 1 (2017), p.1-6.

[2] SC Forbes, MD Kennedy, NB Boule, G Bell Determination of the optimal load setting for arm crank anaerobic testing in men and women. Intelational Journal of Sports Medicine, Vol. 35 (2014), No. 10, p. 835-839.

[3] Barber-Westin, Sue D; Hermeto, Alex A; Noyes, Frank R, et al. A Six-Week Neuromuscular Training Program for Competitive Junior Tennis Players. Journal of Strength \& Conditioning Research. Vol. 24(2010) No. 9, p. 2372-2382.

[4] Forbes SC, Kennedy MD, Bell GJ (2013) Time-motion analysis, heart rate, and physiological characteristics of international canoe polo athletes. Journal of Strength \& Conditioning Research, Vol. 27(2013) No. 20, p. 2816-2822.

[5] Emilio J. Martínez-López, Alberto Grao-Cruces, José E. Moral-García, et al. Intervention for Spanish Overweight Teenagers in Physical Education Lessons. Journal of Sports Science \& Medicine. Vol. 11(2012) No. 2, p. 312-321.

[6] Nicola A. Maffiuletti, Physiological and methodological considerations for the use of neuromuscular electrical stimulation. European Journal of Applied Physiology. Vol. 110(2010) No. 2, p. 223-234

[7] AF Ugras, Effect of high intensity interval training on elite athletes' antioxidant status. Science \& Sports, Vol. 28 (2013) No.5, p.253-259.

[8] JX Li, RCH So, YW Yuan, Muscle strain and cardiovascular stress in fencing competition [C]. Proceeding of the 5th IOC World Congress on Sports Sciences(Sydney, 31 Oct.-5 Nov. 1999). Vol. 5, p.222.

[9] S Anna, S Valery, Aerobic and Anaerobic Capacities of Different Age and Performance Female Fencers. Medsportpress, Vol. 12 (2006) No.2, p.214-217. 